\title{
COVID 19 Diagnostic Tests: A Study of 12,270 Patients to Determine Which Test Offers the Most Beneficial Results
}

\author{
Ali Mahmood $1,2,3,4,5^{*}$, Charisma Gajula ${ }^{6,7}$, Prianka Gajula ${ }^{8}$ \\ ${ }^{1}$ Houston Methodist Specialty Group, Methodist Sugar Land Colon \& Rectal Surgery, Sugar Land, TX, USA \\ ${ }^{2}$ Institute of Academic Medicine, Houston Methodist Hospitals System, Houston, TX, USA \\ ${ }^{3}$ Michael E. DeBakey Department of Surgery, Baylor College of Medicine, Houston, TX, USA \\ ${ }^{4}$ Department of Surgery, College of Medicine, Texas A\&M Health Science Center, Houston Methodist Campus, Houston, TX, USA \\ ${ }^{5}$ Department of Surgery, Weill Cornell Medical College, New York, NY, USA \\ ${ }^{6}$ Department of Colon \& Rectal Surgery, Houston Methodist Hospitals System, Sugar Land, TX, USA \\ ${ }^{7}$ Baylor University, Waco, TX, USA \\ ${ }^{8}$ Department of Medicine, Houston Methodist Hospitals System, Houston, TX, USA \\ Email: ^StrikerMD@hotmail.com, Charisma.gajula@gmail.com, Prianka.gajula@gmail.com
}

How to cite this paper: Mahmood, A., Gajula, C. and Gajula, P. (2020) COVID 19 Diagnostic Tests: A Study of 12,270 Patients to Determine Which Test Offers the Most Beneficial Results. Surgical Science, $11,82-88$.

https://doi.org/10.4236/ss.2020.114011

Received: April 4, 2020

Accepted: April 21, 2020

Published: April 24, 2020

Copyright $\odot 2020$ by author(s) and Scientific Research Publishing Inc. This work is licensed under the Creative Commons Attribution International License (CC BY 4.0).

http://creativecommons.org/licenses/by/4.0/

(c) (i) Open Access

\begin{abstract}
COVID 19 has caused capitulation from healthcare entities all over the world. First described in Hubei, China, the virus has spread to 185 countries, showing little signs of eradication or eradication. There does not exist a medical treatment regimen or a vaccine to address COVID 19 definitively. The best response, to date, has been early diagnosis and immediate isolation or quarantine of the patient, with supportive care. As medical institutions all around the world struggle to keep up with this pandemic, there is not a consensus amongst medical professionals in the rapid diagnosis of this disease entity. Purpose: The purpose of our study was to review the literature and establish a test, or tests, that would aid the clinician in attaining a swift, yet accurate diagnosis. Methods: We searched PubMed and Google scholar and reviewed 32 articles. Keyword searches consisted of COVID 19, pandemic, diagnoses, diagnostic testing, pandemic amongst others. We compared the data obtained from these studies in an effort to find the best diagnostic test. Results: There were a total of 12,270 patients that were in our study [1]-[32]. This is the largest study to date in the literature addressing diagnosis of COVID 19. Fever, cough and fatigue, in that respective order were the most common clinical symptoms. Laboratory findings consisted of leukopenia, elevated erythrocyte sedimentation (ESR) and elevated C-reactive protein, CRP. The gold standard test described in multiple studies was the RT-PCR. Serum assays of IgM and IgG were also drawn and found to be accurate in $93 \%$ of the time. CT Chest was both sensitive and
\end{abstract}


specific, $90 \%$ and $86 \%$. This diagnostic imaging was even more successful when coupled with clinical symptoms and approaching days $7-12$ since the onset of clinical symptoms. Discussion: This is the largest study compiled to address diagnostic testing in COVID 19 patients. The patient population is spread vastly around the world, with access to many reported tests limited in certain countries. Given the significant sensitivity and specificity of diagnostic imaging, in the setting of clinical symptoms, we recommend patient undergo CT Chest in the face of COVID 19 exposure and clinical symptoms. While RT-PCR, IgM-IgG assays are beneficial, isolation, treatment, and possible quarantine of presumptive positive COVID 19 patients (based upon clinical symptoms and imaging) should not be delayed, for fear of increased infectivity and further risk to society at large.

\section{Keywords}

COVID 19, Diagnostic Test, RT-PCR, IgM-IgG, Chest CT, Pandemic

\section{Introduction}

COVID 19 is a pandemic that has seriously impacted our daily living. First described in Wuhan, China, in late December, 2019, the disease has since spread worldwide. Mortality rates have been shocking, with new hot spots emerging daily. There has not been any successful treatment reported. There does not exist a vaccine to prevent the spread of SARS-CoV-2 virus, responsible for COVID 19. The hallmark of treatment has been early detection of the patient population with immediate isolation and/or quarantine. Multiple reports have been published attempting to identify and share the best diagnostic technique. However, there has yet to be a consensus paper outlining and comparing the best test, one that offers both a high sensitivity and specificity.

\section{Purpose}

The purpose of our study was to review the literature and establish a test, or tests, that would aid the clinician in attaining a swift, yet accurate diagnosis.

\section{Methods}

We searched PubMed and Google scholar and reviewed 32 articles. The focus of most of these articles was clinical presentation, history of exposure, real time reverse transcriptase polymerase chain reaction (RT-PCR), IgM and IgG studies, and CT scans of the chest. We compared the data obtained from these studies in an effort to find the best diagnostic test.

\section{Results}

There were a total of 12,270 patients that were in our study [1]-[32]. This is the largest study to date in the literature addressing diagnosis of COVID 19. There 
were significant clinical symptoms associated with COVID 19. Fever, cough and fatigue, in that respective order were the most common. Laboratory findings, from 12,270 patients, consisted of leukopenia, elevated erythrocyte sedimentation (ESR) and elevated C-reactive protein, CRP. The gold standard test described in multiple studies was the RT-PCR. This was found to be accurate in just under $60 \%$ of the patients. Serum assays of IgM and IgG were also drawn and found to be accurate in $93 \%$ of the time. These assays were less available, with the literature yielding them completed less than $40 \%$ (4900 patients) of the time. These tests did have a prolonged turnaround time. CT Chest was both sensitive and specific, $90 \%$ and $86 \%$. This diagnostic imaging was even more successful when coupled with clinical symptoms and approaching days $7-12$ since the onset of clinical symptoms.

\section{Discussion}

COVID 19 does not affect a specific patient population. Although the virus does impact the immunocompromised and elderly population with increased morbidity and mortality, the disease has affected all age ranges, including the pediatric population.

The constellation of clinical symptoms encompass fever, cough and fatigue in decreasing order of presentation. Given the widespread presence of COVID 19, it is important that the clinician entertain this diagnosis when these clinical symptoms are encountered.

Laboratory findings included lymphopenia, elevated erythrocyte sedimentation rate (ESR) and elevated c-reactive protein, CRP. These labs, however are not pathognomonic.

Confirmatory testing has been employed with the use of RT-PCR. The diagnostic accuracy of this test has been $60 \%$ in numerous studies. Some limitations in testing with RT-PCR are that it does require the clinician or technician to obtain an adequate sample. The sputum has the greatest viral load, however it is often difficult to obtain, and places the health care provider at risk. Oropharyngeal and Nasopharayngeal swabs are markedly lower in viral load. One study documented viral loads in the sputum to be 17,429 copies, with throat swabs at 2552 and nasal swabs at 651, almost 27 fold less than sputum. Furthermore, the time from symptom onset to viral load is another variable. Several studies reported viral load to be greatest between days $7-10$ of symptom onset. Nasal swabs on the initial days of symptom onset would easily contribute to a false negative. We recommend sputum samples in these patients to obtain, rather confirm an accurate diagnosis.

Serum IgG-IgM assay was demonstrated to have a testing specificity and sensitivity of close to $90 \%$. While these are outstanding parameters, the feasibility of obtaining serum of all COVID 19 screening patients is a daunting task, with delay in obtaining the results as well. We do advocate using this assay as a confirmatory test. 
The test with the greatest benefit, after evaluating 12,270 patients was the CT Chest, in the presence of clinical symptoms. The CT Chest examination was not dependent upon specimen collection, handling or reporting. There was not any time delay associated with the test, with most results available almost instantly upon completion of the exam. The classic findings appreciated in COVID 19 patients were ground glass opacities in the peripheral and lower lobes. The presence of these findings in the setting of fever, cough and/or fatigue were diagnostic greater than $95 \%$ of the time with specificity greater than $90 \%$. Other findings included bronchial thickening, paving, patchy consolidation, but these were in the setting of ground glass opacifications.

Physical testing shortcomings contributed to the significant failure rate of RT-PCR. The science and molecular biology behind this type of test are not in question, rather the inadequacies and potential insufficient sample volume obtained from the COVID 19 patients. Conversely, CT chest imaging is not dependent upon obtaining samples from patients. Thus the findings have fewer variables associated with obtaining, prepping and testing bodily fluids. The reporting time for diagnostic CT imaging is also the fastest.

There is value in obtaining RT-PCR because there does exist a correlation between viral load and disease state. Patients getting closer to discharge, or recovery, have definitively demonstrated significant deceasing levels of viral load.

Improving diagnostic tests would consist of greater cohesiveness and communication amongst the interdisciplinary physicians addressing the COVID 19 pandemic. Emergency department physicians must coordinate immediate access to CT scans with radiologists, along with expedient return of laboratory data with the clinical pathologist and county or regional health officials. Quicker diagnosis and isolation must be the goal for all involved.

COVID 19 is a pandemic of global proportions. At the time of this article, according to the Johns Hopkins COVID 19 resource center, there are over 1 million cases reported, and a staggering 52,863 deaths. Until the cure can be found, immediate diagnosis and quarantine offer the best chance to mitigate this disease process.

\section{Conflicts of Interest}

The authors declare no conflicts of interest regarding the publication of this paper.

\section{References}

[1] Li, K., Wu, J., Wu, F., Guo, D., Chen, L., Fang, Z. and Li, C. (2020) The Clinical and Chest CT Features Associated with Severe and Critical COVID-19 Pneumonia. Investigative Radiology. https://doi.org/10.1097/RLI.0000000000000672

[2] Salehi, S., Abedi, A., Balakrishnan, S. and Gholamrezanezhad, A. (2020) Coronavirus Disease 2019 (COVID-19): A Systematic Review of Imaging Findings in $919 \mathrm{~Pa}$ tients. American Journal of Roentgenology, 1-7.

https://doi.org/10.2214/AJR.20.23034 
[3] Li, D., Wang, D., Dong, J., Wang, N., Huang, H., Xu, H. and Xia, C. (2020) False-Negative Results of Real-Time Reverse-Transcriptase Polymerase Chain Reaction for Severe Acute Respiratory Syndrome Coronavirus 2: Role of Deep-Learning-Based CT Diagnosis and Insights from Two Cases. Orean Journal of Radiology, 21, 505-508. https://doi.org/10.3348/kjr.2020.0146

[4] Shi, H., Han, X., Jiang, N., Cao, Y., Alwalid, O., Gu, J., Fan, Y. and Zheng, C. (2020) Radiological Findings from 81 Patients with COVID-19 Pneumonia in Wuhan, China: A Descriptive Study. The Lancet Infectious Diseases, pii: S1473-3099(20)30086-4. https://doi.org/10.1016/S1473-3099(20)30086-4

[5] Wang, Y., Dong, C., Hu, Y., Li, C., Ren, Q., Zhang, X., Shi, H. and Zhou, M. (2020) Temporal Changes of CT Findings in 90 Patients with COVID-19 Pneumonia: A Longitudinal Study. Radiology. https://doi.org/10.1148/radiol.2020200843

[6] Li, Y. and Xia, L. (2020) Coronavirus Disease 2019 (COVID-19): Role of Chest CT in Diagnosis and Management. American Journal of Roentgenology, 1-7. https://doi.org/10.2214/AJR.20.22954

[7] Pan, F., Ye, T., Sun, P., Gui, S., Liang, B., Li, L., Zheng, D., Wang, J., Hesketh, R.L., Yang, L. and Zheng, C. (2020) Time Course of Lung Changes on Chest CT during Recovery from 2019 Novel Coronavirus (COVID-19) Pneumonia. Radiology. https://doi.org/10.1148/radiol.2020200370

[8] Xu, Y.H., Dong, J.H., An, W.M., Lv, X.Y., Yin, X.P., Zhang, J.Z., Dong, L., Ma, X., Zhang, H.J. and Gao, B.L. (2020) Clinical and Computed Tomographic Imaging Features of Novel Coronavirus Pneumonia Caused by SARS-CoV-2. Journal of Infection, 80, 394-400. https://doi.org/10.1016/j.jinf.2020.02.017

[9] Wan, S., Xiang, Y., Fang, W., Zheng, Y., Li, B., Hu, Y., Lang, C., Huang, D., Sun, Q., Xiong, Y., Huang, X., Lv, J., Luo, Y., Shen, L., Yang, H., Huang, G. and Yang, R. (2020) Clinical Features and Treatment of COVID-19 Patients in Northeast Chongqing. Journal of Medical Virology. https://doi.org/10.1002/jmv.25783

[10] Wu, J., Wu, X., Zeng, W., Guo, D., Fang, Z., Chen, L., Huang, H. and Li, C. (2020) Chest CT Findings in Patients with Corona Virus Disease 2019 and Its Relationship with Clinical Features. Investigative Radiology. https://doi.org/10.1097/RLI.0000000000000670

[11] Guan, W.J., Ni, Z.Y., Hu, Y., Liang, W.H., Ou, C.Q., He, J., Liu, L., Shan, H., Lei, C.L., Hui, D.S.C., Du, B., Li, L.J., Zeng, G., Yuen, K.Y., Chen, R.C., Tang, C.L., Wang, T., Chen, P.Y., Xiang, J., Li, S.Y., Wang, J.L., Liang, Z.J., Peng, Y.X., Wei, L., Liu, Y., Hu, Y.H., Peng, P., Wang, J.M., Liu, J.Y., Chen, Z., Li, G., Zheng, Z.J., Qiu, S.Q., Luo, J., Ye, C.J., Zhu, S.Y. and Zhong, N.S. (2020) Clinical Characteristics of Coronavirus Disease 2019 in China. China Medical Treatment Expert Group for Covid-19. The New England Journal of Medicine. https://doi.org/10.1056/NEJMoa2002032

[12] Cheng, Z., Lu, Y., Cao, Q., Qin, L., Pan, Z., Yan, F. and Yang, W. (2020) Clinical Features and Chest CT Manifestations of Coronavirus Disease 2019 (COVID-19) in a Single-Center Study in Shanghai, China. American Journal of Roentgenology, 1-6. https://doi.org/10.2214/AJR.20.22959

[13] Wu, J., Feng, C.L., Xian, X.Y., Qiang, J., Zhang, J., Mao, Q.X., Kong, S.F., Chen, Y.C., Pan, J.P., et al. (2020) Novel Coronavirus Pneumonia (COVID-19) CT Distribution and Sign Features. Chinese Journal of Tuberculosis and Respiratory Diseases, 43, E030.

[14] Bernheim, A., Mei, X., Huang, M., Yang, Y., Fayad, Z.A., Zhang, N., Diao, K., Lin, B., Zhu, X., Li, K., Li, S., Shan, H., Jacobi, A. and Chung, M. (2020) Chest CT Findings in Coronavirus Disease-19 (COVID-19): Relationship to Duration of Infection. Radiology. https://doi.org/10.1148/radiol.2020200463 
[15] Bai, H.X., Hsieh, B., Xiong, Z., Halsey, K., Choi, J.W., Tran, T.M.L., Pan, I., Shi, L.B., Wang, D.C., Mei, J., Jiang, X.L., Zeng, Q.H., Egglin, T.K., Hu, P.F., Agarwal, S., Xie, F., Li, S., Healey, T., Atalay, M.K. and Liao, W.H. (2020) Performance of Radiologists in Differentiating COVID-19 from Viral Pneumonia on Chest CT. Radiology. https://doi.org/10.1148/radiol.2020200823

[16] Zhou, S., Wang, Y., Zhu, T. and Xia, L. (2020) CT Features of Coronavirus Disease 2019 (COVID-19) Pneumonia in 62 Patients in Wuhan, China. American Journal of Roentgenology, 1-8. https://doi.org/10.2214/AJR.20.22975

[17] Yoon, S.H., Lee, K.H., Kim, J.Y., Lee, Y.K., Ko, H., Kim, K.H., Park, C.M. and Kim, Y.H. (2020) Chest Radiographic and CT Findings of the 2019 Novel Coronavirus Disease (COVID-19): Analysis of Nine Patients Treated in Korea. Orean Journal of Radiology, 21, 494-500. https://doi.org/10.3348/kjr.2020.0132

[18] Han, R., Huang, L., Jiang, H., Dong, J., Peng, H. and Zhang, D. (2020) Early Clinical and CT Manifestations of Coronavirus Disease 2019 (COVID-19) Pneumonia. American Journal of Roentgenology, 1-6. https://doi.org/10.2214/AJR.20.22961

[19] Zhao, W., Zhong, Z., Xie, X., Yu, Q. and Liu, J. (2020) Relation between Chest CT Findings and Clinical Conditions of Coronavirus Disease (COVID-19) Pneumonia: A Multicenter Study. American Journal of Roentgenology, 1-6. https://doi.org/10.2214/AJR.20.22976

[20] Ai, T., Yang, Z., Hou, H., Zhan, C., Chen, C., Lv, W., Tao, Q., Sun, Z. and Xia, L. (2020) Correlation of Chest CT and RT-PCR Testing in Coronavirus Disease 2019 (COVID-19) in China: A Report of 1014 Cases. Radiology. https://doi.org/10.1148/radiol.2020200642

[21] Xiong, Y., Sun, D., Liu, Y., Fan, Y., Zhao, L., Li, X. and Zhu, W. (2020) Clinical and High-Resolution CT Features of the COVID-19 Infection: Comparison of the Initial and Follow-Up Changes. Investigative Radiology. https://doi.org/10.1097/RLI.0000000000000674

[22] Qin, C., Liu, F., Yen, T.C. and Lan, X. (2020) ${ }_{18}$ F-FDG PET/CT Findings of COVID-19: A Series of Four Highly Suspected Cases. European Journal of Nuclear Medicine and Molecular Imaging, 47, 1281-1286. https://doi.org/10.1007/s00259-020-04734-w

[23] To, K.K., Tsang, O.T., Leung, W.S., Tam, A.R., Wu, T.C., Lung, D.C., Yip, C.C., Cai, J.P., Chan, J.M., Chik, T.S., Lau, D.P., Choi, C.Y., Chen, L.L., Chan, W.M., Chan, K.H., Ip, J.D., Ng, A.C., Poon, R.W., Luo, C.T., Cheng, V.C., Chan, J.F., Hung, I.F., Chen, Z., Chen, H. and Yuen, K.Y. (2020) Temporal Profiles of Viral Load in Posterior Oropharyngeal Saliva Samples and Serum Antibody Responses during Infection by SARS-CoV-2: An Observational Cohort Study. The Lancet Infectious Diseases.

[24] Li, Y., Yao, L., Li, J., Chen, L., Song, Y., Cai, Z. and Yang, C. (2020) Stability Issues of RT-PCR Testing of SARS-CoV-2 for Hospitalized Patients Clinically Diagnosed with COVID-19. Journal of Medical Virology. https://doi.org/10.1002/jmv.25786

[25] Yu, F., Yan, L., Wang, N., Yang, S., Wang, L., Tang, Y., Gao, G., Wang, S., Ma, C., Xie, R., Wang, F., Tan, C., Zhu, L., Guo, Y. and Zhang, F. (2020) Quantitative Detection and Viral Load Analysis of SARS-CoV-2 in Infected Patients. Clinical Infectious Diseases, pii: ciaa345. https://doi.org/10.1093/cid/ciaa345

[26] Li, Y., Hu, Y., Zhang, X., Yu, Y., Li, B., Wu, J., Wu, Y., Xia, X. and Xu, J. (2020) Follow-Up Testing of Viral Nucleic Acid in Discharged Patients with Moderate Type of 2019 Coronavirus Disease (COVID-19). Journal of Zhejiang University. Medical Sciences, 49. (In Chinese) 
[27] Lippi, G., Simundic, A.M. and Plebani, M. (2020) Potential Preanalytical and Analytical Vulnerabilities in the Laboratory Diagnosis of Coronavirus Disease 2019 (COVID-19). Clinical Chemistry and Laboratory Medicine. https://doi.org/10.1515/cclm-2020-0285

[28] Xiong, Z., Fu, L., Zhou, H., Liu, J.K., Wang, A.M., Huang, Y., Huang, X., Yi, B., Wu, J., Li, C.H., Quan, J., Li, M., Leng, Y.S., Luo, W.J., Hu, C.P. and Liao, W.H. (2020) Construction and Evaluation of a Novel Diagnosis Process for 2019-Corona Virus Disease. National Medical Journal of China, 100, E019.

[29] Liu, R., Han, H., Liu, F., Lv, Z., Wu, K., Liu, Y., Feng, Y. and Zhu, C. (2020) Positive Rate of RT-PCR Detection of SARS-CoV-2 Infection in 4880 Cases from One Hospital in Wuhan, China, from Jan to Feb 2020. Clinica Chimica Acta, 505, 172-175. https://doi.org/10.1016/j.cca.2020.03.009

[30] Xie, C., Jiang, L., Huang, G., Pu, H., Gong, B., Lin, H., Ma, S., Chen, X., Long, B., Si, G., Yu, H., Jiang, L., Yang, X., Shi, Y. and Yang, Z. (2020) Comparison of Different Samples for 2019 Novel Coronavirus Detection by Nucleic Acid Amplification Tests. International Journal of Infectious Diseases, 93, 264-267. https://doi.org/10.1016/j.ijid.2020.02.050

[31] Li, Z., Yi, Y., Luo, X., Xiong, N., Liu, Y., Li, S., Sun, R., Wang, Y., Hu, B., Chen, W., Zhang, Y., Wang, J., Huang, B., Lin, Y., Yang, J., Cai, W., Wang, X., Cheng, J., Chen, Z., Sun, K., Pan, W., Zhan, Z., Chen, L. and Ye, F. (2020) Development and Clinical Application of a Rapid IgM-IgG Combined Antibody Test for SARS-CoV-2 Infection Diagnosis. Journal of Medical Virology. https://doi.org/10.1002/jmv.25727

[32] Li, Y.Y., Wang, W.N., Lei, Y., Zhang, B., Yang, J., Hu, J.W., Ren, Y.L. and Lu, Q.F. (2020) Comparison of the Clinical Characteristics between RNA Positive and Negative Patients Clinically Diagnosed with 2019 Novel Coronavirus Pneumonia. Chinese Journal of Tuberculosis and Respiratory Diseases, 43, E023. 